\title{
Assessment and development first requires a deeper understanding of unique categories of senior leaders: A focus on CEOs and C-level executives - ERRATUM
}

Nathan J. Hiller and Suzanne J. Peterson

The original publication of this Commentary [1] was written in response to the Focal Article "A Critical Evaluation of the State of Assessment and Development for Senior Leaders" by Douglas H. Reynolds, Cynthia D. McCauley, Suzanne Tsacoumis and The Jeanneret Symposium Participants [2].

The editorial note that introduced this Commentary should have referenced the Focal Article addressed by the Commentary.

The publisher regrets this oversight.

\section{References:}

1. Hiller, N., \& Peterson, S. (2019). Assessment and development first requires a deeper understanding of unique categories of senior leaders: A focus on CEOs and C-level executives. Industrial and Organizational Psychology, 12(2), 211-214. doi: 10.1017/iop.2019.24

2. Reynolds, D., McCauley, C., \& Tsacoumis, S. (2018). A critical evaluation of the state of assessment and development for senior leaders. Industrial and Organizational Psychology, 11(4), 630-652. doi: 10.1017/iop.2018.84 